\title{
CONTRIBUIÇÕES DO PIBID DO IF SERTÃO-PE AO ENSINO-APRENDIZAGEM DE QUÍMICA
}

\section{CONTRIBUTIONS OF PIBID OF IF SERTÃO-PE TO THE TEACHING-LEARNING OF CHEMISTRY}

Lucas Ribeiro Coelho ${ }^{1}$ ORCID iD: 0000-0002-1753-2041

Carlos Alailson Licar Rodrigues ${ }^{2}$

ORCID iD: 0000-0002-5426-1121

Jackson Ronie Sá-Silva ${ }^{3}$

ORCID iD: 0000-0001-9607-3674

\section{RESUMO}

Esta pesquisa, de perspectiva documental, objetivou realizar um levantamento dos trabalhos do Pibid do Instituto Federal de Educação, Ciência e Tecnologia do Sertão Pernambucano (IF Sertão-PE), que contribuíram para o ensino-aprendizagem da disciplina de Química nas escolas da Educação Básica, objeto de intervenção. O estudo pautou-se pelos princípios da pesquisa qualitativa e análise documental. Analisou-se, por meio da técnica de análise de conteúdo, os resumos dos trabalhos apresentados na Jornada de Iniciação à Docência (JID) do IF Sertão-PE, nos anos de 2016 e 2017, que fizeram parte das atividades didático-pedagógicas relacionadas ao ensino de conteúdos da disciplina de Química nas escolas. Os resultados apontaram que o Pibid do IF Sertão-PE contribuiu para o desenvolvimento e a utilização de novas ações didático-metodológicas no ensino de Química na sala de aula, proporcionando aprendizagens significativas dos discentes assistidos, além de contribuir para o desenvolvimento de atividades pedagógicas que promoveram a inclusão social de alunos, uma vez que a vivência de situações reais da rotina escolar e da sala de aula na Educação Básica favorecem o desenvolvimento de novas práticas educacionais em busca de um ensino-aprendizado inovador, contextual, cidadão e investigativo no ensino de Química.

Palavras-chave: Ensino de Química. Formação de professores. Pibid.

\begin{abstract}
This research, made from a documentary perspective, aimed to carry out a survey of the Pibid works of the Federal Institute of Education, Science and Technology of the Sertão Pernambucano (IF Sertão-PE),

\footnotetext{
${ }^{1}$ Graduando em Licenciatura em Química pelo Instituto Federal de Educação, Ciência e Tecnologia do Sertão Pernambucano (IF Sertão-PE), Petrolina, Pernambuco, Brasil. Endereço para correspondência: Rua Maria Luíza de Araújo Gomes Cabral, S/N, João de Deus, Petrolina, Pernambuco, Brasil, CEP: 56316-686. E-mail: lucasribeirocoelho18@gmail.com.

${ }^{2}$ Doutorando em Ciência Animal pela Universidade Estadual do Maranhão (UEMA), Campus Paulo VI, São Luís, Maranhão, Brasil. Endereço para correspondência: Av. Lourenço Vieira da Silva, n. ${ }^{\circ}$ 1000, Cidade Universitária Paulo VI, Jardim São Cristóvão, São Luís, Maranhão, Brasil, CEP: 65055-310. E-mail: carlos_licar@ hotmail.com. ${ }^{3}$ Doutor em Educação pela Universidade do Vale do Rio dos Sinos (UNISINOS). Pós-Doutor em Educação pela Universidade Federal do Rio Grande do Sul (UFRGS). Professor Adjunto do Departamento de Biologia da Universidade Estadual do Maranhão (DBIO-UEMA). Professor do Programa de Pós-Graduação em Educação da Universidade Estadual do Maranhão (PPGE-UEMA / Mestrado Profissional), Campus Paulo VI, São Luís, Maranhão, Brasil. Endereço para correspondência: Av. Lourenço Vieira da Silva, n. ${ }^{\circ}$ 1000, Cidade Universitária Paulo VI, Jardim São Cristóvão, São Luís, Maranhão, Brasil, CEP: 65055-310. E-mail: prof.jacksonronie.uema@gmail.com.
} 
which contributed to the teaching-learning of the discipline of Chemistry in the schools of the Basic Education, object of intervention. The study was guided by the principles of qualitative research and document analysis. It was analyzed, through the technique of content analysis, the abstracts of the works presented in the Journey of Initiation to Teaching (JID) of IF Sertão-PE, in the years 2016 and 2017, which were part of the didactic-pedagogical activities related to the teaching Chemistry content in schools. The results showed that the IF Sertão-PE Pibid contributed to the development and use of new didactic-methodological actions in the teaching of Chemistry in the classroom, providing significant learning for the assisted students, in addition to contributing to the development of pedagogical activities that promoted the social inclusion of students, since the experience of real situations of school routine and classroom in Basic Education favor the development of new educational practices in search of innovative, contextual, citizen and investigative teaching in the teaching of Chemistry.

Keywords: Chemistry teaching. Teacher training. Pibid.

\section{INTRODUÇÃO}

O ensino de Química tem despertado o interesse de muitos pesquisadores no campo da educação, assim como em pesquisas relacionadas ao ensino de Ciências, cujas contribuições estão expressas em diversos trabalhos disponíveis na literatura. Isso demonstra que as discussões levantadas nessa área são essenciais para o desenvolvimento da aprendizagem e para o enfrentamento dos desafios relativos ao ensino desse componente curricular (SANTOS; PORTO, 2013).

Pensar sobre a qualidade do ensino de Química conduz, de forma direta ou indireta, aos diálogos a respeito da formação dos professores dessa área, que desempenham um papel fundamental no processo formativo dos alunos nos espaços escolares. Na concepção de Teixeira Júnior e Rodrigues Filho (2015), refletir sobre a qualidade da Educação Básica é importante e conduz a pensar sobre a formação docente, visto que formar e capacitar os educadores atuantes na profissão ainda se constitui como um dos principais desafios.

Nesse contexto, a Coordenação de Aperfeiçoamento de Pessoal de Nível Superior (Capes) criou o Programa Institucional de Bolsa de Iniciação à Docência (Pibid), sendo um programa que se configura como uma das principais ações que visam atender aos objetivos da Política Nacional de Formação de Professores da Educação Básica, por meio da Lei n. ${ }^{\circ} 11.502$, de julho de 2007. O objetivo é estimular as universidades e os Institutos Federais, que ofertam cursos de licenciatura, a elaborarem projetos institucionais de iniciação à docência e a participarem das seleções de Instituições de Ensino Superior (IESs) para a implementação do programa (BRASIL, 2007; MARTINS; DULLIUS, 2017).

Os objetivos do Pibid estão direcionados às práticas de iniciação à docência, abrangendo diversas áreas do conhecimento, entre as quais destacam-se Linguagens, Matemática, Ciências da Natureza e Ciências Humanas, conforme a Base Nacional Comum Curricular (BNCC), 
sendo Língua Portuguesa, Matemática, Ciências, Física, Química, Biologia e Alfabetização as áreas prioritárias de iniciação à docência. O objetivo é inserir o (a) aluno (a) licenciando (a) no cotidiano escolar, já no início da graduação, para a elaboração e execução de atividades didático-pedagógicas fundamentais para o processo de ensino e aprendizagem. Amorim e Vieira (2016, p. 133) apontam que a iniciativa tem oportunizado "[...] uma possibilidade de fortalecimento da formação docente mais integrada com a realidade educacional, favorecendo a construção da identidade das licenciaturas nas instituições”.

Dessa maneira, o interesse em realizar este trabalho partiu da necessidade de interpelar se as intervenções didático-pedagógicas desenvolvidas nas escolas de Educação Básica pelos (as) licenciandos (as), por meio do Pibid, propiciam implicações para o ensino e a aprendizagem em uma área que, segundo Alves e Ribeiro (2020), é considerada pelos estudantes, em alguns casos, de difícil aprendizagem: a Química.

No Instituto Federal de Educação, Ciência e Tecnologia do Sertão Pernambucano (IF Sertão-PE), as propostas de ensino desenvolvidas pelos participantes do programa são, via de regra, apresentadas na Jornada de Iniciação à Docência (JID). Este evento é organizado e realizado anualmente no âmbito do Pibid em parceria com a Pró-Reitoria de Ensino do IF Sertão-PE. O objetivo é divulgar as ações desenvolvidas pelos discentes por meio do Pibid e promover a discussão dos impactos do programa nas escolas da Educação Básica e na formação do profissional docente (NETO et al., 2018).

Considerando esses aspectos, o estudo foi norteado pela seguinte questão-problema: quais as contribuições do Pibid do IF Sertão-PE para o processo de ensino-aprendizagem de Química na escola de Educação Básica? Partindo disso, supôs-se que o programa tem contribuído para superar dificuldades no que diz respeito à compreensão de conteúdos da disciplina de Química, melhorando, consequentemente, o desempenho dos alunos assistidos e aperfeiçoando a atividade professoral.

Portanto, este estudo objetivou realizar um levantamento das contribuições proporcionadas pelo Pibid do IF Sertão-PE para o ensino e a aprendizagem de Química na escola de Educação Básica, a partir de uma análise dos resumos apresentados na Jornada de Iniciação à Docência (JID) do IF Sertão-PE nos anos de 2016 e 2017.

\section{REFERENCIAL TEÓRICO}

Os cursos de licenciatura, historicamente, foram apresentados como uma alternativa para as pessoas que se interessavam pelo estudo da Química, mas não conseguiam prosseguir 
no aprendizado de disciplinas específicas da matriz curricular do curso, a exemplo de Química Inorgânica, Química Orgânica e Físico-Química. Desse modo, a alternativa oferecida aos discentes era cursar matérias de núcleo comum aos cursos de licenciatura, a exemplo de Didática, Filosofia da Educação, Psicologia da Educação, Produção Textual, entre outras (CHASSOT, 2004). Esses professores, portanto, não compreendiam que tais conhecimentos eram e continuam sendo importantes para uma aprendizagem significativa dos alunos.

Diante desses obstáculos encontrados na formação docente, dificuldades foram se estruturando em meio aos modos de ensinar e aprender. Alves e Ribeiro (2020, p. 303) enfatizam que os conteúdos programáticos da disciplina de Química “[...] normalmente exigem um determinado nível de abstração, que os estudantes não estão habituados a lidar”. Frente à pluralidade discente e às suas particularidades de aprendizagem no que diz respeito ao ritmo de estudo, bem como ao surgimento de novas metodologias e estratégias educativas, o ensino tradicional, muitas vezes centralizado na memorização dos conteúdos, não tem um resultado positivo no processo de ensino-aprendizagem dos alunos (SILVA; SILVA; PAULA, 2016).

Em alguns casos, os docentes que praticam o ensino de Química na educação formal experimentam dificuldades para garantir a aprendizagem dos seus alunos. Importa citar a estrutura física dos estabelecimentos de ensino, falta de laboratórios, além da escassez de recursos metodológicos/pedagógicos para a realização do ensino. Entretanto, é válido destacar que o docente precisa despertar o interesse pela utilização de métodos capazes de estimular a aprendizagem e a motivação dos discentes (CHAVES; MEOTTI, 2019).

Tanto nas séries iniciais e finais do Ensino Fundamental quanto no Ensino Médio, há um público diversificado, muitos deles adolescentes que se encontram em fase de transformação e desenvolvimento. Diante disso, torna-se oportuna a compreensão de seus fatores motivacionais, visando contribuir com o conhecimento da disciplina. Tal aspecto deve ser analisado sob um viés investigativo, considerando ações didáticas eficazes para o estudo da Química, permitindo que o professor conheça e aplique os procedimentos pedagógicos diversificados que tenham reflexos na qualidade da aprendizagem dos educandos (DIONÍZIO et al., 2019). Nessa perspectiva, sugere-se que o docente, em seu recurso pedagógico, execute ações de ensino de forma ativa e estabeleça a interação e participação dos discentes por meio de atividades lúdicas, da experimentação e da investigação, questões que muito contribuem para o envolvimento do público em sala de aula (ZAPATEIRO et al., 2017).

No entanto, de forma a lidar com essas situações, o professor deve estar capacitado e munido de conhecimento dos conteúdos curriculares necessários ao exercício das atividades pedagógicas relacionadas à disciplina que lecionará. Contudo, apenas isso não é suficiente para 
a prática do trabalho pedagógico (TARDIF, 2012). Tratando-se da Química, Chassot (2004) defende a ideia de que o profissional licenciado, mesmo que não execute atividades laboratoriais específicas como os bacharéis em Química e Química Industrial, merecem uma formação completa por excelência, uma vez que irão formar recursos humanos importantes, ensinando-lhes uma nova forma de olhar e compreender o mundo e seu cotidiano sob a luz da Química.

Nessa perspectiva, os cursos de formação de professores devem proporcionar experiências a partir de ações capazes de articular os conhecimentos do curso de graduação e os adquiridos durante a prática laboral/docente (IMBERNÓN, 2004). Assim, torna-se evidente a necessidade de os (as) licenciandos (as) vivenciarem e experimentarem a dinâmica da atividade docente no seu futuro espaço de atuação: a escola. Conforme Nóvoa (2009), é preciso que os professores tenham uma formação constante, sendo executada durante o exercício da profissão, permitindo, dessa forma, a construção da identidade profissional docente. $\mathrm{O}$ autor reforça que enquanto a prática da formação professoral ocorrer fora da realidade escolar, as mudanças e os resultados decorrentes no campo profissional serão poucos e ineficazes.

Dessa maneira, a forma com que as questões inerentes à formação de professores são discutidas tem gerado preocupações relacionadas à implementação de práticas de ensino de qualidade, tendo reflexo na necessidade de uma melhor qualificação desses profissionais. É importante considerar a integração de estratégias pedagógicas que contribuam e facilitem a práxis didático-pedagógica nos diversos campos do saber (TEIXEIRA JÚNIOR; RODRIGUES FILHO, 2015).

Nesse contexto, em 2007, a Capes, em parceria com o Ministério da Educação (MEC) e o Fundo Nacional de Desenvolvimento da Educação (FNDE), criou o Programa Institucional de Bolsa de Iniciação à Docência (Pibid), visando incentivar e valorizar a formação de docentes para atuação na Educação Básica, principalmente nas áreas de Química, Física, Biologia e Matemática, devido à carência de professores nessas áreas (MARTINS; DULLIUS, 2017; SANTOS; MENEZES, 2018). O Programa apresenta os seguintes objetivos:

I - Incentivar a formação de docentes em nível superior para a educação básica. II - Contribuir para a valorização do magistério.

III - Elevar a qualidade da formação inicial de professores nos cursos de licenciatura, promovendo a integração entre educação superior e educação básica.

IV - Inserir os licenciandos no cotidiano de escolas da rede pública de educação, proporcionando-lhes oportunidades de criação e participação em experiências metodológicas, tecnológicas e práticas docentes de caráter inovador e interdisciplinar que busquem a superação de problemas identificados no processo de ensinoaprendizagem.

V - Incentivar escolas públicas de educação básica, mobilizando seus professores 
como coformadores dos futuros docentes e tornando-as protagonistas nos processos de formação inicial para o magistério.

VI - Contribuir para a articulação entre teoria e prática necessárias à formação dos docentes, elevando a qualidade das ações acadêmicas nos cursos de licenciatura (BRASIL, 2020, p. 2).

O Pibid concede bolsas a licenciandos (as) participantes de projetos de iniciação à docência, para planejarem e desenvolverem atividades didático-pedagógicas que complementem as ações dos professores, em parceria com escolas da rede de Educação Básica do país. Nas IESs, as bolsas se estendem também a outras funções, tais como: coordenador institucional (docente responsável pelo programa na IES), coordenador de área (docente responsável pela iniciação à docência na sua área de atuação na IES) e professor supervisor (docente da Educação Básica responsável pela supervisão das atividades desenvolvidas pelos pibidianos nas escolas) (AMORIM; VIEIRA, 2016; BRASIL, 2020).

Conforme Teixeira Júnior e Rodrigues Filho (2015), o programa vem se consolidando como uma das mais importantes iniciativas educacionais relacionadas à formação inicial de professores no país, possibilitando aos discentes o contato direto com o seu campo profissional, bem como o desenvolvimento de metodologias inovadoras no espaço escolar. Nessa ótica, Martins e Dullius (2017) destacam a articulação entre a universidade e as escolas públicas, mediante o compartilhamento de ideias e conhecimentos que auxiliam na desenvolução do processo de ensino e aprendizagem na Educação Básica. Nesse sentido, a formação dos professores representa uma grande conquista do Pibid.

\section{METODOLOGIA}

Neste trabalho, optou-se por uma abordagem qualitativa e documental. Na pesquisa qualitativa, os dados coletados na investigação são analisados indutivamente, tendo o processo e seu significado como os focos principais de análise (PRODANOV; FREITAS, 2013). Sendo de cunho documental, a pesquisa é desenvolvida a partir de métodos e técnicas para a apreensão, compreensão e análise de documentos dos mais variados tipos, que são a base do trabalho de investigação, visando o acesso às fontes pertinentes (SÁ-SILVA; ALMEIDA; GUINDANI, 2009).

Escolheu-se, entre as várias IESs que atuam com o Pibid, o IF Sertão-PE como lócus de investigação, em virtude de ser a instituição que formou grande parte dos professores de Química atuantes em diversos municípios do sertão de Pernambuco. O corpus de análise deste estudo foi delimitado a partir dos trabalhos (resumos simples) apresentados nas JIDs do IF 
Sertão-PE, nos anos de 2016 e 2017 (IV JID, realizada no campus Petrolina; e V JID, realizada no campus Serra Talhada, respectivamente), que constam no livro digital Trilhas do Ensino: Pibid e Formação Docente no IF Sertão-PE, organizado pela Pró-Reitoria de Ensino do IF Sertão-PE e publicado em 2018.

A obra pode ser considerada como livro de resumos do evento e está dividida em três partes: a primeira relata os desafios e perspectivas do Pibid no IF Sertão-PE; a segunda socializa três artigos sobre as vivências nos projetos do Pibid; e a terceira apresenta os resumos apresentados nas JIDs de 2016 e 2017. Essa última parte foi o foco de análise deste trabalho e contém 118 produções provenientes de projetos pedagógicos até então desenvolvidos por estudantes dos cursos de licenciatura em Computação, Física, Música e Química nas escolas de Educação Básica, por meio do Pibid.

Em busca de respostas à questão-problema e de alcançar o objetivo da investigação, os trabalhos que constam no livro foram analisados à luz dos pressupostos teóricos da análise de conteúdo proposta por Bardin (2011), envolvendo as seguintes etapas para a sua condução: $1^{\mathrm{a}}$ pré-análise (fase de organização); $2^{\mathrm{a}}$ - exploração do material (fase de categorizar o material); e $3^{\mathrm{a}}$ - tratamento dos resultados (fase de inferência e interpretação dos achados). Assim, a análise de conteúdo mostra-se como um conjunto de técnicas de análise das comunicações, utilizando procedimentos sistemáticos e objetivos de descrição do conteúdo das mensagens (BARDIN, 2011).

$\mathrm{Na}$ primeira etapa, visando identificar produções com resultados finais referentes à realização de atividades didático-pedagógicas diretamente relacionadas ao ensino de Química, realizou-se a leitura completa do livro para garantir o controle seletivo do corpus. Nessa fase, alguns trabalhos, embora citassem o ensino de Química, não foram incluídos na seleção, em decorrência de não deixarem evidente a relação com algum conteúdo da disciplina, ou por terem sido apresentados em fase de desenvolvimento dos projetos nas escolas e possuírem apenas resultados esperados, superficiais e/ou incompletos.

A partir desses critérios de inclusão, foram selecionados 19 trabalhos dos 55 apresentados na IV JID, e 21 dos 63 apresentados na V JID, totalizando 40 resumos relacionados à temática. Posteriormente, cada um dos trabalhos selecionados recebeu um código de identificação, sendo de A1 a A19 para os resumos da IV JID, e B1 a B21 para os resumos da V JID, conforme detalhamento exposto no Quadro 1.

$\mathrm{Na}$ segunda etapa, após leitura minuciosa do material selecionado, os textos foram organizados em três categorias, que adquiriram forma no decorrer do processo de análise. Estas foram produzidas de acordo com as ideias que apresentaram similaridade, a saber: instrumentos 
didáticos, experimentação e Tecnologias da Informação e Comunicação (TICs). Na terceira etapa, ocorreu a interpretação dos dados obtidos na análise dos resumos incluídos em cada categoria, acompanhada de discussões qualitativas, considerando suas implicações para o ensino e a aprendizagem de Química na escola de Educação Básica.

\begin{tabular}{|c|c|c|c|}
\hline $\begin{array}{c}\text { Código do } \\
\text { trabalho }\end{array}$ & $\begin{array}{l}\text { Ano da } \\
\text { JID }\end{array}$ & Título do trabalho & Autores do trabalho \\
\hline A1 & 2016 & $\begin{array}{l}\text { A arte e a Química auxiliando na } \\
\text { Educação Inclusiva }\end{array}$ & $\begin{array}{l}\text { ROCHA, G. N. S. A. O.; FREITAS, A. } \\
\text { R. A. G.; AMORIM, D. C. G. }\end{array}$ \\
\hline $\mathrm{A} 2$ & 2016 & $\begin{array}{l}\text { Observação de aula por bolsista Pibid e } \\
\text { proposta metodológica: a } \\
\text { experimentação e sua importância no } \\
\text { ensino de concentração e diluição de } \\
\text { soluções }\end{array}$ & $\begin{array}{l}\text { NASCIMENTO, A. C. N.; } \\
\text { ALBUQUERQUE, A. R.; AUGUSTO } \\
\text { FILHA, V. L. S.; SÁ, C. L. S. G. }\end{array}$ \\
\hline A3 & 2016 & $\begin{array}{c}\text { Projeto de intervenção pedagógica Super } \\
\text { Química: experimentos de Química } \\
\text { enriquecendo o Proeja }\end{array}$ & $\begin{array}{l}\text { GOMES, L. B.; ALVES, A. T. F.; } \\
\text { CARVALHO, K. C.; CRUZ, L. C.; } \\
\text { RODRIGUES, M. C.; SANTOS, N. B.; } \\
\text { AMORIM, P. R.; SILVA, S. A. L., } \\
\text { SANTOS, M. M. }\end{array}$ \\
\hline A4 & 2016 & $\begin{array}{l}\text { Química Orgânica: um ensino } \\
\text { contextualizado para jovens e adultos }\end{array}$ & $\begin{array}{l}\text { RODRIGUES, N. M. C.; DIAS, M. A. } \\
\text { M.; VIEIRA, G. A. B.; ALMEIDA, M. } \\
\text { D. S. }\end{array}$ \\
\hline A5 & 2016 & $\begin{array}{l}\text { Tabela naval: uso do lúdico no ensino da } \\
\text { tabela periódica }\end{array}$ & $\begin{array}{c}\text { CASSIANO, M. A. N.; SILVA, C. M.; } \\
\text { FIGUEIRÔA, J. A.; AUGUSTO } \\
\text { FILHA, V. L. S.; SOUZA, M. J. S. }\end{array}$ \\
\hline A6 & 2016 & $\begin{array}{c}\text { Tabela periódica: os alimentos e suas } \\
\text { composições químicas - mitos e } \\
\text { verdades }\end{array}$ & $\begin{array}{l}\text { SANTOS, M. B.; OLIVEIRA, P. S.; } \\
\text { ALMEIDA, M. D. S. }\end{array}$ \\
\hline A7 & 2016 & $\begin{array}{l}\text { WhatsApp: uma proposta interdisciplinar } \\
\text { no ensino de Química }\end{array}$ & $\begin{array}{l}\text { LIMA, T. A. SILVA, V. S.; CANDIDO, } \\
\text { R, A.; AUGUSTO FILHA, V. L. S. }\end{array}$ \\
\hline A8 & 2016 & Química, câmera, ação! & $\begin{array}{l}\text { SILVA, B. A. S.; ALMEIDA, M. I. B.; } \\
\text { ALMEIDA, M. D. S.; VIEIRA, G. A. } \\
\text { B. }\end{array}$ \\
\hline A9 & 2016 & $\begin{array}{l}\text { Trilha química: desenvolvimento de } \\
\text { conhecimento dos hidrocarbonetos e das } \\
\text { funções oxigenadas }\end{array}$ & $\begin{array}{l}\text { MOURA, L. A.; CANDIDO, R. A.; } \\
\text { ALBUQUERQUE, A. R.; SÁ, C. L. S. } \\
\text { G. }\end{array}$ \\
\hline A10 & 2016 & $\begin{array}{l}\text { Trilha química: uso de jogo educativo e } \\
\text { lúdico no ensino de Química Orgânica }\end{array}$ & $\begin{array}{c}\text { SÁ, J. G.; VENANCIO, K. S.; } \\
\text { ALBUQUERQUE, A. R.; SÁ, C. L. S. } \\
\text { G.; AUGUSTO FILHA, V. L. S. }\end{array}$ \\
\hline A11 & 2016 & $\begin{array}{l}\text { Quimemória periódica: desenvolvendo o } \\
\text { raciocínio no ensino de Química }\end{array}$ & $\begin{array}{c}\text { SÁ, S. S.; CASSIANO, M. A. N.; } \\
\text { NASCIMENTO, A. C. N.; SOUZA, J.; } \\
\text { SÁ, C. L. S. G.; AUGUSTO SILVA, V. } \\
\text { L. S. }\end{array}$ \\
\hline A12 & 2016 & $\begin{array}{l}\text { Dominó das funções orgânicas: } \\
\text { revisando e estimulando o aprendizado }\end{array}$ & $\begin{array}{l}\text { MOURA, A. M.; CANDIDO, R. A.; } \\
\text { ALBUQUERQUE, A. R.; SÁ, C. L. S. } \\
\text { G. }\end{array}$ \\
\hline A13 & 2016 & $\begin{array}{l}\text { Funções inorgânicas no cotidiano: } \\
\text { promovendo a pesquisa e } \\
\text { experimentação com alunos do Ensino } \\
\text { Médio }\end{array}$ & $\begin{array}{l}\text { FERREIRA, L. T. L.; SILVA FILHO, } \\
\text { N.; SÁ, J. F. N.; SÁ, C. L. S. G.; } \\
\text { AUGUSTO FILHA, V. L. S. }\end{array}$ \\
\hline A14 & 2016 & Gincana química: uma forma de revisar & $\begin{array}{l}\text { SANTOS, L. P.; OLIVEIRA, B. S.; } \\
\text { VIEIRA, G. A. B.; ALMEIDA, M. D. } \\
\text { S. }\end{array}$ \\
\hline A15 & 2016 & $\begin{array}{l}\text { A utilização de jogos didáticos como } \\
\text { ferramenta no processo de ensino- }\end{array}$ & $\begin{array}{l}\text { NETO, J. A.; MARREIROS, M. A.; } \\
\text { VIEIRA, G. A. B.; ALMEIDA, M. D. }\end{array}$ \\
\hline
\end{tabular}




\begin{tabular}{|c|c|c|c|}
\hline & & $\begin{array}{l}\text { aprendizagem em Química no Ensino } \\
\text { Médio }\end{array}$ & S. \\
\hline A16 & 2016 & $\begin{array}{l}\text { Aplicação de jogos lúdicos no ensino da } \\
\text { Química }\end{array}$ & $\begin{array}{l}\text { SANTOS, E. C.; SILVA, M. J. M.; } \\
\text { VIEIRA, I. A.; MELO, A.; } \\
\text { MARQUES, V. S. }\end{array}$ \\
\hline A17 & 2016 & $\begin{array}{l}\text { Baralho químico: utilização de cartas no } \\
\text { incentivo ao aprendizado do diagrama de } \\
\text { Linus Pauling da tabela periódica }\end{array}$ & $\begin{array}{l}\text { VENANCIO, S. V.; MORAES, E. R.; } \\
\text { ALBUQUERQUE, A. R.; SÁ, C. L. S. } \\
\text { G.; AUGUSTO FILHA, V. L. S. }\end{array}$ \\
\hline A18 & 2016 & $\begin{array}{l}\text { Contextualização dos conceitos de ácido } \\
\text { e base para o ensino de Química }\end{array}$ & $\begin{array}{l}\text { NASCIMENTO, G. L.; OLIVEIRA, P. } \\
\text { M. S.; GUEDES, A. M. A. }\end{array}$ \\
\hline A19 & 2016 & $\begin{array}{l}\text { Curtindo a Química: uma proposta de } \\
\text { aprendizagem utilizando redes sociais }\end{array}$ & $\begin{array}{c}\text { SANTOS, A. C. F.; SÁ, A. P.; } \\
\text { FERREIRA, L. T. L.; MENEZES, R. } \\
\text { C.; CANDIDO, R. A.; } \\
\text { ALBUQUERQUE, A. R. }\end{array}$ \\
\hline B1 & 2017 & $\begin{array}{l}\text { A contribuição do jogo na construção de } \\
\text { conhecimentos de substâncias e misturas: } \\
\text { uma proposta didática vivenciada no } \\
\text { Pibid }\end{array}$ & $\begin{array}{l}\text { MELO, J.; SANTOS, E. C.; VIEIRA, I. } \\
\text { A.; SILVA, M. J. M; SILVA, A. N. }\end{array}$ \\
\hline B2 & 2017 & $\begin{array}{l}\text { Abordagem de conteúdo de forma } \\
\text { dinâmica: revisando ligações químicas } \\
\text { com jogo quebra-cabeças feito no Excel } \\
\text { e massa de modelar com palitos roliços } \\
\text { de madeira }\end{array}$ & $\begin{array}{l}\text { SILVA, V. S.; NASCIMENTO, A. C. } \\
\text { N.; ALVES, P. R.; SÁ, C. L. S. G. }\end{array}$ \\
\hline B3 & 2017 & $\begin{array}{l}\text { Confecção dos modelos atômicos, } \\
\text { explorando a visão dimensional no } \\
\text { ensino de Química }\end{array}$ & $\begin{array}{l}\text { SILVA, V. S.; NASCIMENTO, A. C. } \\
\text { N.; NUNES, S. L.; SÁ, C. L. S. G. }\end{array}$ \\
\hline B4 & 2017 & $\begin{array}{l}\text { Construindo materiais didáticos para o } \\
\text { ensino de Química }\end{array}$ & $\begin{array}{l}\text { CASTRO, D. M. R.; SILVA, B. A.; } \\
\text { ALMEIDA, M. D. S.; VIEIRA, G. A. } \\
\text { B. }\end{array}$ \\
\hline B5 & 2017 & $\begin{array}{l}\text { Construindo ovos de chocolate e } \\
\text { estudando suas composições químicas }\end{array}$ & $\begin{array}{l}\text { SILVA, L. B. O.; DELMONDES, A. } \\
\text { S.; PATRÍCIO, T.; SILVA, A. N. }\end{array}$ \\
\hline B6 & 2017 & $\begin{array}{c}\text { Elaboração e utilização de tabela } \\
\text { periódica interativa no processo de } \\
\text { ensino-aprendizagem de alunos cegos, } \\
\text { surdos e ouvintes }\end{array}$ & $\begin{array}{l}\text { SANTOS, C. A. S.; ANDRADE, J. R.; } \\
\text { NUNES, J. T. L.; NOGUEIRA, R. M.; } \\
\text { ALMEIDA, M. D. S.; VIEIRA, G. A. } \\
\text { B. }\end{array}$ \\
\hline$\overline{B 7}$ & 2017 & $\begin{array}{l}\text { Fermentação alcóolica como alternativa } \\
\text { para o ensino da função orgânica álcool }\end{array}$ & $\begin{array}{l}\text { TOSTES, B. V. A.; PIRES, I. C. B.; } \\
\text { LEITE, H. B.; VALE, I. H. V.; VIIRA, } \\
\text { G. A. B.; COSTA, K. B. S. }\end{array}$ \\
\hline B8 & 2017 & $\begin{array}{l}\text { Inclusão social: uma nova forma de } \\
\text { inclusão }\end{array}$ & $\begin{array}{l}\text { SOUZA, P. C.; SOUZA, E. S.; } \\
\text { SOUZA, M. M.; BEZERRRA, C. L.; } \\
\text { VIEIRA, G. A. B.; ALMEIDA, M. D. } \\
\text { S. }\end{array}$ \\
\hline B9 & 2017 & Meu elemento amigo (secreto) & $\begin{array}{l}\text { SILVA, M. M. A.; MARCELINO, R. } \\
\text { M.; SILVA, A. N. }\end{array}$ \\
\hline $\mathrm{B} 10$ & 2017 & $\begin{array}{l}\text { O aprendizado da Química básica e a sua } \\
\text { influência no despertar da motivação dos } \\
\text { discentes }\end{array}$ & $\begin{array}{l}\text { VENANCIO, K. S.; ALVES, P. R.; } \\
\text { SOUZA, J.; ALBUQUERQUE, A. R.; } \\
\text { SÁ, C. L. S. G. }\end{array}$ \\
\hline B11 & 2017 & $\begin{array}{c}\text { O estudo da Química no cotidiano e na } \\
\text { vida acadêmica do educando e professor: } \\
\text { fixação do assunto propriedades físicas e } \\
\text { químicas da matéria através de um lúdico } \\
\text { na escola Edaf de Floresta-PE }\end{array}$ & $\begin{array}{c}\text { SOUZA, C. K. S.; SOUZA, J.; } \\
\text { ALBUQUERQUE, A. R.; SÁ, C. L. S. } \\
\text { G. }\end{array}$ \\
\hline B12 & 2017 & $\begin{array}{l}\text { O uso da gincana como estratégia no } \\
\text { processo aprendizagem no ensino de } \\
\text { hidrocarbonetos }\end{array}$ & $\begin{array}{l}\text { ALVES, P. R.; VENANCIO, K. S.; SÁ, } \\
\text { C. L. S. G. }\end{array}$ \\
\hline B13 & 2017 & $\begin{array}{l}\text { Petróleo e produção de cordéis: uma } \\
\text { vivência interdisciplinar no ensino- } \\
\text { aprendizagem de Química }\end{array}$ & $\begin{array}{l}\text { MENEZES, R. C.; SANTOS, A. C. F.; } \\
\text { MACIEL, M. G. S.; FERREIRA, J. L.; } \\
\text { BORGES, A. P. V.; SÁ, C. L. S. G.; } \\
\text { ALBUQUERQUE, A. R. }\end{array}$ \\
\hline
\end{tabular}




\begin{tabular}{|c|c|c|c|}
\hline B14 & 2017 & $\begin{array}{l}\text { Química na alimentação animal: uma } \\
\text { proposta interdisciplinar no ensino de } \\
\text { agropecuária }\end{array}$ & $\begin{array}{l}\text { MORAES, E. R.; DANTAS, F. R.; } \\
\text { BORGES, A. P.; ALBUQUERQUE, A. } \\
\text { R.; SÁ, C. L. S. G. }\end{array}$ \\
\hline B15 & 2017 & $\begin{array}{c}\text { Química on-line: a utilização de recursos } \\
\text { tecnológicos no processo de } \\
\text { aprendizagem }\end{array}$ & $\begin{array}{l}\text { CRUZ, F. C.; SILVA, A. C.; } \\
\text { RODRIGUES, L. C. S.; } \\
\text { MARREIROS, M. A. ALMEIDA, M. } \\
\text { D. S. }\end{array}$ \\
\hline B16 & 2017 & $\begin{array}{l}\text { Química verde - trabalhando com } \\
\text { descarte de pilhas e baterias }\end{array}$ & $\begin{array}{c}\text { NASCIMENTO, G. B.; SILVA, W. F.; } \\
\text { SILVA, A. N. }\end{array}$ \\
\hline B17 & 2017 & $\begin{array}{l}\text { Rompendo as barreiras do ensino de } \\
\text { Química através da construção de } \\
\text { materiais alternativos }\end{array}$ & $\begin{array}{l}\text { VALE, I. H.; ANDRADE, A. C.; } \\
\text { NETO, J. A.; VIEIRA, G. A. B.; } \\
\text { ALMEIDA, M. D. S. }\end{array}$ \\
\hline B18 & 2017 & $\begin{array}{c}\text { Show do milhão químico: um método de } \\
\text { ensino-aprendizagem para o estudo da } \\
\text { Química }\end{array}$ & $\begin{array}{c}\text { SILVA, V. S.; SANTOS, J. C. S.; } \\
\text { BORGES, A. P. V. }\end{array}$ \\
\hline B19 & 2017 & $\begin{array}{l}\text { Teste de condutividade elétrica: } \\
\text { compreendendo o comportamento } \\
\text { elétrico da matéria }\end{array}$ & $\begin{array}{c}\text { CAVALCANTI, A. C. N. F.; SOUZA, } \\
\text { E. L.; ALBUQUERQUE, A. R.; SÁ, C. } \\
\text { L. S. G. }\end{array}$ \\
\hline B20 & 2017 & $\begin{array}{l}\text { Uso de jogos didáticos como estratégia } \\
\text { metodológica para a inclusão no ensino } \\
\text { de Química }\end{array}$ & $\begin{array}{l}\text { AMORIM, A. S.; FONSECA, A. S.; } \\
\text { SANTOS, L. P.; TRIGO, S. P. M.; } \\
\text { ALMEIDA, M. D. S.; VIEIRA, G. A. } \\
\text { B. }\end{array}$ \\
\hline B21 & 2017 & $\begin{array}{l}\text { Utilização de jogos lúdicos: dominó } \\
\text { químico como auxílio da tabela periódica } \\
\text { no ensino de Química }\end{array}$ & $\begin{array}{c}\text { BARBOSA, E. C. F. C.; SOUZA, E. } \\
\text { L.; ALBUQUERQUE, A. R.; SÁ, C. L. } \\
\text { S. G. }\end{array}$ \\
\hline
\end{tabular}

Quadro 1 - Descrição e detalhamento dos resumos apresentados nas IV JID e V JID do IF Sertão-PE, nos anos de 2016 e 2017 , constituintes do corpus do estudo

Fonte: Elaborado pelos autores (2020)

\section{ANÁLISES E RESULTADOS}

Nesta seção, serão apresentados e discutidos os achados que abrangem três focos principais destacados nos 40 trabalhos selecionados das IV JID e V JID: instrumentos didáticos, experimentação e Tecnologias de Informação e Comunicação (TICs). Esses focos foram categorizados com o intuito de sistematizar os trabalhos para uma melhor compreensão dos dados e qualificá-los de modo a nortear essa investigação, que tem como base o ensino e a aprendizagem.

De acordo com o detalhamento mostrado no Quadro 2, a maioria dos trabalhos (26) pertence à primeira categoria; já a minoria (4) se enquadra na terceira categoria. Percebeu-se que houve um disparate entre as categorias e inferiu-se que o desenvolvimento de instrumentos didáticos foi um foco dos estudantes. A baixa expressividade de trabalhos relacionados às tecnologias da informação pode estar relacionada à falta de apoio e de recursos tecnológicos no âmbito das escolas da Educação Básica. Segundo Silva et al. (2019), a utilização de instrumentos lúdicos no ensino de Química possibilita não apenas a memorização e aprendizagem dos conteúdos, mas, também, uma formação crítica e cidadã dos alunos envolvidos. 


\begin{tabular}{|c|c|c|c|}
\hline Categoria & Descrição da categoria & $\begin{array}{c}\text { Códigos dos trabalhos } \\
\text { pertencentes à categoria }\end{array}$ & $\begin{array}{c}\text { Número de } \\
\text { trabalhos }\end{array}$ \\
\hline $\begin{array}{c}\text { Instrumentos } \\
\text { didáticos }\end{array}$ & $\begin{array}{c}\text { Desenvolvimento de materiais } \\
\text { didáticos, como jogos, visando a } \\
\text { auxiliar o processo de ensino- } \\
\text { aprendizagem }\end{array}$ & $\begin{array}{c}\mathrm{A} 1, \mathrm{~A} 5, \mathrm{~A} 6, \mathrm{~A} 9, \mathrm{~A} 10, \mathrm{~A} 11, \mathrm{~A} 12, \\
\mathrm{~A} 14, \mathrm{~A} 15, \mathrm{~A} 16, \mathrm{~A} 17, \mathrm{~A} 18, \mathrm{~B} 1, \\
\mathrm{~B} 2, \mathrm{~B} 3, \mathrm{~B} 4, \mathrm{~B} 6, \mathrm{~B} 8, \mathrm{~B} 9, \mathrm{~B} 11, \\
\mathrm{~B} 12, \mathrm{~B} 13, \mathrm{~B} 17, \mathrm{~B} 18, \mathrm{~B} 20, \mathrm{~B} 21\end{array}$ & 26 \\
\hline Experimentação & $\begin{array}{c}\text { Realização de experimentos } \\
\text { baseados em conteúdo, visando a } \\
\text { auxiliar o processo de ensino- } \\
\text { aprendizagem }\end{array}$ & $\begin{array}{c}\mathrm{A} 2, \mathrm{~A} 3, \mathrm{~A} 4, \mathrm{~A} 13, \mathrm{~B} 5, \mathrm{~B} 7, \mathrm{~B} 10, \\
\mathrm{~B} 14, \mathrm{~B} 16, \mathrm{~B} 19\end{array}$ & 10 \\
\hline TICs & $\begin{array}{c}\text { Utilização de TICs, visando a } \\
\text { auxiliar o processo de ensino- } \\
\text { aprendizagem }\end{array}$ & $\mathrm{A} 7, \mathrm{~A} 8, \mathrm{~A} 19, \mathrm{~B} 15$ & 4 \\
\hline
\end{tabular}

Quadro 2 - Categorias dos trabalhos constituintes do corpus do estudo Fonte: Elaborado pelos autores (2020)

Na primeira categoria de análise, verificou-se que os trabalhos envolveram os seguintes conteúdos curriculares: tabela periódica, funções orgânicas, modelos atômicos, diagrama de Linus Pauling, ligações químicas, equipamentos de laboratório, ácidos e bases, reações químicas, substâncias e misturas, compostos orgânicos e propriedades físicas e químicas da matéria. Para a abordagem desses conteúdos em sala de aula, os bolsistas do Pibid desenvolveram diferentes materiais didáticos e atividades lúdicas, tais como: tabelas periódicas, modelos atômicos construídos com materiais alternativos, cartilhas e vários jogos didáticos/lúdicos, pensados de acordo com a realidade presenciada em sala de aula.

Investigando detalhadamente os objetivos, metodologia e resultados de tais intervenções didático-pedagógicas, notou-se que a maioria pautou-se pela elaboração de diferentes jogos, sendo intitulados de: "tabela naval", "jogo da memória", "trilha química”, "quimemória periódica", "dominó das funções orgânicas”, "gincana química”, "dados das ligações”, "jogo das adivinhações", "baralho químico", "roleta química", "quebra-cabeça", "meu elemento amigo (secreto)", "verdade ou mentira", "relacione-me", "corrida contra o tempo", "incompletus", "jornal do hidrô", "show do milhão químico", "jogo de argolas", "perfil 5", "ludo" e "imagem \& ação".

Os objetivos traçados pelos projetos dessa linha metodológica foram alcançados. Os resultados, embora situados em diferentes abordagens de conteúdo, se mantiveram semelhantes aos de A16, ao enfatizar que os jogos contribuíram para uma aprendizagem mais significativa sobre os conteúdos, observando que a utilização de atividades lúdicas no estudo da Química torna a aula mais atraente e inovadora, podendo garantir um maior sucesso no processo de ensino-aprendizagem.

Com base nesse caráter uniforme dos dados, compreendeu-se que os jogos são 
importantes ferramentas didáticas a serem utilizadas no ensino de Química. Cunha (2012) pontua que a concepção de ensino impulsionado pela motivação do aluno na aprendizagem se tornou um desafio para o trabalho docente. Assim, os jogos, como instrumentos didáticos capazes de estimular aspectos motivacionais nos estudantes, vêm sendo utilizados nas escolas, direcionando as aulas de forma dinâmica e contextualizada.

Especificamente nos trabalhos A1, A15, B8, B17 e B20, analisou-se que os bolsistas do Pibid se dedicaram à preparação de instrumentos inclusivos direcionados ao ensino, em virtude da diversidade de alunos no espaço de atuação. Em A1, os autores destacam que a construção de uma tabela periódica em grande escala proporcionou aos alunos o desenvolvimento da coordenação motora, além da aprendizagem do conteúdo de forma espontânea. Em A15, similarmente, a execução de um jogo como metodologia de ensino em uma turma com alunos surdos, em parceria com uma intérprete, levou a concluir que, com recursos adequados, é possível obter bons resultados, independentemente das necessidades especiais dos alunos.

Por meio da preparação de uma cartilha na Linguagem Brasileira de Sinais (Libras), dando ênfase à Química, em B8 é pontuado que, além de ter ajudado na aprendizagem dos conteúdos, o trabalho proporcionou também o fortalecimento do vínculo entre alunos surdos e ouvintes. Nessa perspectiva inclusiva, em B17 apresentou-se a construção de uma tabela periódica em braile (sistema de escrita tátil utilizado por pessoas cegas ou com baixa visão), possibilitando um processo de ensino-aprendizagem mais eficaz, pois tornou o ambiente mais dinâmico e atrativo para os alunos. Constatou-se um resultado semelhante em B20, uma vez que a adaptação de jogos didáticos estabeleceu um ensino-aprendizagem participativo e colaborativo, com efetiva inclusão.

Levando-se em consideração a visão de Paulo, Borges e Delou (2018), tais intervenções na perspectiva da Educação Inclusiva no ensino de Química são importantes para vivenciar o contexto de uma sala de aula inclusiva, acreditando que não só a elaboração de material educativo, mas, também, a formação inicial do professor é um processo importante para que se tenha um ensino mais inclusivo. Mesmo que o futuro docente não possua experiência na Educação Especial, a participação na escolarização de alunos com necessidades especiais permite a aquisição de práticas educacionais para a diversidade, percebendo que todos os educandos, com necessidades especiais ou não, possuem iguais direitos e possibilidades de concluírem os estudos de maneira exitosa (SILVA; DAMASCENO, 2015).

Na segunda categoria de análise, os trabalhos, entre as suas etapas, realizaram práticas experimentais fundamentadas nos conteúdos de soluções, misturas, funções inorgânicas, composição química, funções orgânicas, química dos alimentos, eletroquímica e condutividade 
elétrica da matéria. Como resultado, evidenciou-se que a experimentação e a investigação contribuíram para o ensino-aprendizagem, resultando numa evolução significativa na compreensão dos alunos no que diz respeito aos conceitos fundamentais de Química, bem como no rendimento escolar.

Constatando a importância no processo de ensino e os resultados produtivos na aprendizagem discente, A3 sugere um acréscimo de aulas experimentais por parte dos docentes, de forma a garantir a qualidade do ensino e uma prática pedagógica eficaz. Dessa forma, essas considerações estão de acordo com as expostas por Gabriel, Rodríguez e Fluente (2016), ao destacarem que a aplicação de experimentos químicos permite cumprir com os objetivos da disciplina e contribui para que os alunos aprendam a fazer na prática, pensar, questionar, perguntar, sugerir e criticar, que são elementos-chave para a prática investigativa, além de incentivarem a curiosidade pela Química e o gosto pela ciência, melhorando os resultados de aprendizagem.

$\mathrm{Na}$ terceira categoria de análise, constatou-se a utilização de TICs como ferramentas pedagógicas no contexto educacional, como o aplicativo WhatsApp, a rede social Facebook e recursos audiovisuais, trabalhando com a produção e/ou compartilhamento de vídeos, imagens e paródias, visando abordar reações químicas, química dos agrotóxicos, tratamento de água e reciclagem. Em A19, destaca-se a ideia de que o uso de redes sociais sob um viés pedagógico estimulou os discentes a utilizarem-nas com o intuito educativo. Isso evidencia que a tecnologia pode ser uma ferramenta essencial e aliada ao processo de ensino-aprendizagem, para além da sala de aula, nas diversas áreas do conhecimento.

Os trabalhos enquadrados nessa categoria realizaram considerações semelhantes às de B15, ao deixar claro que trabalhar a Ciência Química, em conjunto com a tecnologia, instiga os estudantes à participação e à proatividade na busca de conhecimentos construídos, tanto de forma individual quanto coletiva. Havendo interação social entre os educandos, terá, consequentemente, ressignificação do conhecimento, oferecendo, desse modo, cientificidade ao objeto.

Assim, os resumos incluídos nessa categoria dialogam com Dionizío et al. (2019), ao pontuarem que as TICs têm se mostrado como uma estratégia educacional que pode ser associada ao ensino de Química, como possibilidade para tornar o discente protagonista do processo de ensino-aprendizagem. Essas tecnologias são capazes de proporcionar comunicação, distribuir e compartilhar informações referentes aos conteúdos ministrados na disciplina, possibilitando o desenvolvimento do trabalho pedagógico de forma inovadora e acompanhado de resultados qualitativos. 
A partir do que já foi exposto na análise dos trabalhos das três categorias (instrumentos didáticos, experimentação e TICs), observou-se que, na área de Química, as intervenções didático-pedagógicas desenvolvidas pelos bolsistas do Pibid do IF Sertão-PE tiveram, em suas raízes, a tentativa de modificar a rotina da sala de aula e superar dificuldades geralmente encontradas no processo educativo. Para tanto, os participantes do programa recorreram ao planejamento de metodologias de ensino que pudessem ser postas em prática para orientar os alunos da Educação Básica na construção do conhecimento em Química, atribuindo significado e importância aos conteúdos estudados.

Nesse sentido, na perspectiva do ensino por investigação apresentado neste trabalho, os projetos analisados estão diretamente voltados para o quarto objetivo do programa, conforme descrito pela Capes (BRASIL, 2020). Trata-se de algo que proporciona aos futuros professores momentos oportunos de criação e participação em experiências metodológicas, tecnológicas e práticas docentes de caráter inovador, buscando a superação de problemas identificados no processo de ensino-aprendizagem, tendo em vista que uma disciplina deve sempre levar em consideração estratégias metodológicas favoráveis para o aprendizado dos estudantes, possibilitando que alcancem os objetivos definidos (OLIVEIRA; CAETANO, 2018).

Partindo dessa premissa, sob uma perspectiva da formação docente, as atividades didático-pedagógicas nas escolas de Educação Básica contribuíram significativamente para a formação docente dos (as) licenciandos (as) em Química participantes do Pibid. As experiências adquiridas a partir das situações concretas da rotina escolar e da sala de aula auxiliaram no desenvolvimento de novas práticas educacionais em busca de um ensino-aprendizado qualitativo, eficiente e eficaz. Logo, esse pensamento vai ao encontro de Araújo et al. (2017), ao acrescentarem que essas ações são importantes para a qualidade na formação inicial de docentes de Química para atuarem na Educação Básica. Portanto, resgata-se a ideia de Nóvoa (2009) acerca da importância da formação de professores no âmbito da profissão docente.

\section{CONSIDERAÇÕES}

Conclui-se, por meio dos resultados da análise dos trabalhos apresentados nas IV JID e V JID do IF Sertão-PE, que as atividades didático-pedagógicas analisadas nesta investigação contribuíram para o desenvolvimento e utilização de novas metodologias de ensino nas aulas de Química, proporcionando aprendizagens significativas no processo de ensino-aprendizagem que podem ser aplicadas nas escolas da Educação Básica. 
Evidenciou-se que as ações efetivadas nas escolas foram bem-planejadas e buscaram superar problemas diagnosticados no processo educativo, destacando-se, sobretudo, as atividades situadas na perspectiva da Educação Inclusiva, as quais favoreceram a aprendizagem dos estudantes com ou sem necessidades especiais, promovendo, dessa forma, a inclusão social.

Os resultados permitiram ainda considerar a possibilidade de os (as) licenciandos (as) terem contato com situações reais da rotina escolar e da sala de aula na Educação Básica e refletirem acerca do processo de ensino-aprendizagem. Esse processo, durante a formação inicial para a docência, se constitui como uma contribuição do Pibid, permitindo a vivência dos desafios da escola não mais como alunos, mas numa perspectiva profissional docente. Nesse sentido, o Pibid reforça a ideia de que a formação inicial de professores necessita ocorrer de forma constante e participativa no ambiente escolar, estreitando a relação entre os cursos de licenciatura das IESs e a realidade da Educação Básica brasileira.

Portanto, acredita-se que as ideias e os conhecimentos obtidos neste estudo podem auxiliar não apenas os professores de Química, mas também de outros componentes curriculares a desenvolverem práticas pedagógicas inovadoras, que possam fortalecer as relações entre os sujeitos durante o processo de ensino-aprendizagem.

\section{REFERÊNCIAS}

ALVES, Handerson Rodrigo; RIBEIRO, Marcel Thiago Damasceno. Uma proposta de sequência didática para o ensino de soluções. REAMEC - Rede Amazônica de Educação em Ciências e Matemática, Cuiabá, v. 8, n. 1, p. 302-322, jan./abr. 2020. Disponível em: http://periodicoscientificos.ufmt.br/ojs/index.php/reamec/article/view/9748/pdf_1. Acesso em: 17 maio 2020.

AMORIM, Delza Cristina Guedes; VIEIRA, Josenilton Nunes. Enfoques epistemológicos do Programa Institucional de Bolsa de Iniciação à Docência/Pibid para a formação docente.

Semiárido De Visu, Petrolina, v. 4, n. 3, p. 132-145, 2016. Disponível em: https://periodicos.ifsertao-pe.edu.br/ojs2/index.php/semiaridodevisu/article/view/258/175. Acesso em: 21 maio 2020.

ARAÚJO, Naiara Veras de et al. As contribuições do Pibid no ensino de Química: atividades alternativas a partir da confecção de ferramentas pedagógicas provenientes de materiais de baixo-custo. Conexões - Ciência e Tecnologia, [S. 1.], v. 10, n. 4, p. 35-41, jan. 2017. Disponível em: http://conexoes.ifce.edu.br/index.php/conexoes/article/view/981. Acesso em: 22 maio 2020.

BARDIN, Laurence. Análise de conteúdo. São Paulo: Edições 70, 2011.

BRASIL. Lei n. ${ }^{\circ}$ 11.502, de 11 de julho de 2007. Modifica as competências e a estrutura organizacional da fundação Coordenação de Aperfeiçoamento de Pessoal de Nível Superior CAPES. Brasília: Presidência da República, 2007. Disponível em: 
http://www.planalto.gov.br/ccivil_03/_Ato2007-2010/2007/Lei/L11502.htm. Acesso em: 3 jun. 2020.

BRASIL. Ministério da Educação - MEC. Coordenação de Aperfeiçoamento de Pessoal de Nível Superior - CAPES. Edital no 2/2020. Brasília: 06 jan. 2020. Disponível em: https://capes.gov.br/images/novo_portal/editais/editais/06012019-EDITAL-2-2020PIBID.pdf. Acesso em: 15 maio 2020.

CHASSOT, Attico Inacio. Para que(m) é útil o ensino? 2. ed. Canoas: Ulbra, 2004.

CHAVES, Julciana Ferreira; MEOTTI, Paula Regina Melo. Dificuldades no ensino aprendizagem e estratégias motivacionais da disciplina de Química do Instituto Federal do Amazonas - Campus Humaitá. Revista EDUCAmazônica - Educação, Sociedade e Meio Ambiente, Humaitá, v. 12. n. 1, p. 206-224, jan./jun. 2019. Disponível em: https://periodicos.ufam.edu.br/index.php/educamazonia/article/download/5771/4491/. Acesso em: 28 maio 2020.

CUNHA, Marcia Morin da. Jogos no ensino de Química: considerações teóricas para sua utilização em sala de aula. Química Nova na Escola, v. 4, n. 2, p. 92-98, maio 2012. Disponível em: http://qnesc.sbq.org.br/online/qnesc34_2/07-PE-53-11.pdf. Acesso em 29 maio 2020.

DIONÍZIO, Thaís Petizero et al. O uso de tecnologias da informação e comunicação como ferramenta educacional aliada ao ensino de Química. EaD em Foco, v. 9, n. 1, p. 1-15, dez. 2019. Disponível em:

https://eademfoco.cecierj.edu.br/index.php/Revista/article/view/809/502. Acesso em: 30 maio 2020.

GABRIEL, Ernesto Dumba; RODRÍGUEZ, Juan Jesús Mondéjar; FLUENTE, Magali Torres. Processo de ensino-aprendizagem da Química nas Escolas Médias do Moxico sustentado no experimento químico escolar. Química Nova na Escola, São Paulo, v. 38, n. 3, p. 251-260, ago. 2016. Disponível em: http://qnesc.sbq.org.br/online/qnesc38_3/10-EQF-03-14.pdf. Acesso em: 28 maio 2020.

IMBERNÓN, Francisco. Formação docente e profissional: formar-se para a mudança e incerteza. 4. ed. São Paulo: Cortez, 2004.

MARTINS, Danielle Juliana Silva; DULLIUS, Maria Madalena. Um estudo de caso sobre os saberes docentes na visão dos licenciandos participantes do Pibid do IF Sertão PE. Crítica Educativa, Sorocaba, v. 3, n. 2, p. 359-373, jan./jun. 2017. Disponível em: http://dx.doi.org/10.22476/revcted.v3i2.208. Acesso em: 20 maio 2020.

NETO, Maria Marli de Melo; ANJOS, Débora Santos Carvalho dos; AMORIM, Delza Cristina Guedes; SILVEIRA, Kamilla Barreto (org.). Trilhas do ensino: Pibid e formação docente no IF Sertão-PE. Petrolina: IF Sertão-PE, 2018. Disponível em: http://releia.ifsertaope.edu.br:8080/jspui/handle/123456789/473. Acesso em: 20 mar. 2020.

NÓVOA, António. Para uma formação de professores construída dentro da profissão. Revista Educacion, Madrid, 2009. Disponível em:

http://www.revistaeducacion.educacion.es/re350/re350_09por.pdf. Acesso em: 22 mar. 2020. 
OLIVEIRA, Carla Maria Bispo Padrel; CAETANO, Fernando José Pires. Desafiando o paradigma do ensino da Química: o contributo da Universidade Aberta de Portugal. Revista Pesquisa e Debate em Educação, Juiz de Fora, v. 8, n. 2, p. 275-291, 2018. Disponível em: http://www.revistappgp.caedufjf.net/index.php/revista1/article/view/268/180. Acesso em: 19 maio 2020.

PAULO, Paula Rodrigues N. F.; BORGES, Marcia Narcizo; DELOU, Cristina Maria C. Produção de materiais didáticos acessíveis para o ensino de Química Orgânica inclusivo. Revista Areté | Revista Amazônica de Ensino de Ciências, [S. 1.], v. 11, n. 23, p. 116-125, mar. 2018. Disponível em:

http://periodicos.uea.edu.br/index.php/arete/article/view/881. Acesso em: 30 maio 2020.

PRODANOV, Cleber Cristiano; FREITAS, Ernani Cesar de. Metodologia do trabalho científico: métodos e técnicas da pesquisa e do trabalho acadêmico. 2. ed. Novo Hamburgo: Feevale, 2013. Disponível em: http://www.feevale.br/Comum/midias/8807f05a-14d0-4d5bb1ad-1538f3aef538/E-book\%20Metodologia\%20do\%20Trabalho\%20Cientifico.pdf. Acesso em: 18 maio 2020.

SÁ-SILVA, Jackson Ronie; ALMEIDA, Cristóvão Domingos de; GUINDANI, Joel Felipe. Pesquisa documental: pistas teóricas e metodológicas. Revista Brasileira de História e Ciências Sociais, v. 1, n. 1, p. 1-15, 2009. Disponível em: https://periodicos.furg.br/rbhcs/article/view/10351/pdf. Acesso em: 12 jun. 2020.

SANTOS, Joseana Vieira dos; MENEZES, Maria Cilene Freire de. As contribuições formativas do Pibid na formação inicial dos professores dos cursos de licenciaturas. Revista de Educação da Universidade Federal do Vale do São Francisco, Petrolina, v. 8, n. 16, p. 99-126, maio/ago. 2018. Disponível em:

http://www.periodicos.univasf.edu.br/index.php/revasf/article/view/245/156. Acesso em: 18 maio 2020.

SANTOS, Wildson Luiz Pereira dos; PORTO, Paulo Alves. A pesquisa em ensino de Química como área estratégica para o desenvolvimento da Química. Química Nova, São Paulo, v. 36, n. 10, p. 1570-1576, 2013. Disponível em: https://doi.org/10.1590/S010040422013001000014. Acesso em: 20 maio 2020.

SILVA, Elio de Angeles Nicole da et al. Jogando com a Química: um instrumento de aprendizagem no ensino da eletroquímica. Revista de Estudos e Pesquisas sobre Ensino Tecnológico (EDUCITEC), Manaus, v. 5, n. 10, p. 39-54, mar. 2019. Disponível em: https://sistemascmc.ifam.edu.br/educitec/index.php/educitec/article/view/434/257. Acesso em: 2 jun. 2020.

SILVA, Nínive Matias Rodrigues; SILVA, Wanderson Diogo Andrade da; PAULA, Neidimar Lopes Matias de. O ensino de Química frente à experimentação: conhecendo diferentes realidades. Revista Debates em Ensino de Química, v. 2, n. 2, p. 70-78, out. 2016. Disponível em:

http://www.journals.ufrpe.br/index.php/REDEQUIM/article/view/1316/1075. Acesso em: 17 maio 2020.

SILVA, Wanderson Diogo Andrade da; DAMASCENO, Mônica Maria Siqueira. A Química 
no contexto da educação especial: o professor, o ensino e a deficiência visual. Revista Debates em Ensino de Química, v. 1, n. 1, p. 20-28, out. 2015. Disponível em:

http://200.17.137.114/index.php/REDEQUIM/article/view/1261/1023. Acesso em: 5 jun. 2020.

TARDIF, Maurice. Saberes docentes e formação profissional. 14. ed. Petrópolis: Vozes, 2012.

TEIXEIRA JÚNIOR, José Gomes; RODRIGUES FILHO, Guimes. Perfil dos alunos de licenciaturas em química que atuam como bolsistas do Programa Institucional de Bolsa de Iniciação à Docência e as influências para sua formação inicial. Química Nova na Escola, São Paulo, v. 37, n. 4, p. 305-311, nov. 2015. Disponível em: http://dx.doi.org/10.5935/01048899.20150052. Acesso em: 21 maio 2020.

ZAPATEIRO, Gean Aparecido et al. Material didático como estratégia de ensino e de aprendizagem das ligações químicas. ACTIO: Docência em Ciências, Curitiba, v. 2, n. 2, p. 211-233, jul./set. 2017. Disponível em:

https://periodicos.utfpr.edu.br/actio/article/download/6862/4538. Acesso em: 18 maio 2020.

Submetido em: 13 de junho de 2020.

Aprovado em: 25 de julho de 2020. 